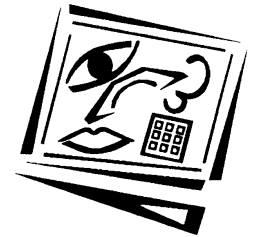

\title{
An information-summarising instruction strategy for improving the web-based problem solving abilities of students
}

Gwo-Jen Hwang

National Taiwan University of Science and Technology

Fan-Ray Kuo

National University of Tainan

As knowledge rapidly expands and accumulates, training and assessing students' information searching ability for solving problems on the Internet has become an important and challenging issue. This research aims to improve the web-based problem solving abilities of primary school students by employing an information summarising approach for improving their skills in using keywords and extracting proper information. Moreover, a web-based learning environment is employed to record and analyse the online information searching behaviours of students. An experiment has been conducted to evaluate the effectiveness of this innovative approach. The experimental results show that the information summarising training significantly improved the performance of the students in the experimental group in terms of using keywords, selecting information resources and extracting important content. Therefore, it was concluded that the innovative approach has a significant impact on promoting the web-based problem solving abilities of students.

\section{Introduction}

With the rapid development of the Internet and computer technology, learning how to search for useful information via the Internet has become an important issue in recent years (Liu, Liu \& Hwang, 2010; Tsai \& Tsai, 2003; Tsai, Tsai \& Hwang, 2011). Researchers have also indicated the importance of skills for retrieving information efficiently and effectively from the great deal of data found on the Internet (Hwang, Tsai, Tsai, Tseng \& Tseng, 2008; Tseng, Hwang, Tsai \& Tsai, 2009).

Previous studies have also shown that most children have difficulty in searching for information on the Internet. Children are usually unfamiliar with the usage of the search engines, mismatch keywords or misuse Boolean symbols, so that they are likely to retrieve incorrect or inappropriate information (Bilal, 2000; Spink \& Xu, 2000). That is, the web-based information searching behaviours of most elementary school students are incorrect owing to the lack of related training. In addition, while trying to read and use the search results, students usually retrieve data based on the titles of web pages instead of the content, which is likely to cause them to choose incomplete or irrelevant information. This could be ascribed to their weak content comprehension and summarising abilities. Therefore, the training of content comprehension and summarising skills has become an important and challenging issue. 
To cope with these problems, in this study, an information summarising instruction strategy was employed to improve students' information summarising ability, including keyword usage, information resource selecting and content extracting An experiment has been conducted to evaluate the effectiveness of the innovative approach by randomly assigning sixty-seven fifth-grade elementary school students into an experimental group and a control group. From the experimental results, it was found that the approach significantly improved the performance of the students in using keywords, selecting information resources and extracting important content, and hence their web-based problem solving ability was enhanced as well.

\section{Literature review}

Teaching students to obtain valuable information efficiently from the Internet has attracted the attention of researchers in the past decade. Various strategies concerning web-based information searching have been proposed (Chiou, Hwang \& Tseng, 2009). For example, Ackerman and Karen (2005) proposed a detailed ten-step procedure for online information searching:

1. Identifying important concepts about the problems to be solved.

2. Selecting keywords that match these concepts.

3. Identifying possible synonyms within the keywords.

4. Selecting a search method, such as Proximity search or Boolean search.

5. Choosing a search engine.

6. Reading instructions on the main page of the search engine, such as "Help", "Advanced Search", and "Common Questions."

7. Creating appropriate words and phrases for the search engine.

8. Evaluating the searched results and checking the relevance with problems.

9. Fixing the search method and repeating Steps 2 to 4 if necessary.

10. Trying different search engines with identical search methods and repeating Steps 6 to 9.

Within the curriculum related to web-based information searching offered by elementary schools, students usually encounter several difficulties during their webbased problem solving process, such as determining appropriate keywords for the problems, selecting relevant web sites to browse, and extracting essential information from the searched results. Researchers have indicated that students would obtain relevant data efficiently from a variety of web sites if they could use precise and proper keywords; that is, most of the irrelevant data could be weeded out at this earliest stage, and hence their cognitive load could be significantly reduced (Amadieu, Tricot \& Marine, 2009; Washington, 1977; Hwang \& Chang, 2011; Madrid, Oostendorp \& Melguizo, 2008).

Furthermore, students also encounter problems in evaluating the relevance of the web sites to the problems and extracting the information they need (Wallace, Kupperman, Krajcik \& Soloway, 2000; Lorenzen, 2002; MaKinster, Beghetto \& Plucker, 2002; Wu \& Tsai, 2007; So \& Kim, 2009; Ladbrook \& Probert, 2011). That is, the ability of students to comprehend the content of the sites they access plays a critical role in retrieving data from a large amount of web information that matches the keywords. If students are equipped with the ability to grasp the key points of the problems, they may be able to seek efficiently what they need from the Internet with appropriate keywords, and then extract content effectively from the searched results. On the contrary, if they fail to 
identify the key points of the problem, the whole problem solving process is likely to be inefficient (Pharo \& Jarvelin, 2004; Wormeli, 2005; Brickell \& Herrington, 2006; Tu, Shih \& Tsai, 2008; Susar \& Akkaya, 2009; Antiqueira, Oliveira, Costa \& Nunes, 2009; Veletsianos \& Doering, 2010). Hence, this study attempts to employ an information summarising instruction strategy to enhance the information comprehension and summarising abilities of the students; hopefully, their web-based problem solving ability can be improved as well.

Researchers have indicated that learners are likely to gain good learning achievements if they are able to summarise all concepts from the articles they are studying (Williams, Taylor \& DeCani, 1984). As mentioned previously, during the process of solving a problem, identification of key concepts for a problem before searching for information is essential, and is a determinant of how problem solvers evaluate the relevance between the searched data from web sites and the problems, as well as how they extract the information they need. That is, enhancing the information summarising ability of students could be helpful to them in comprehending the problems to be solved and the information to be derived (Hare, Rabinowitz \& Schieble, 1989; So \& Kim, 2009; Cheng, 2009).

\section{Research design}

In this study, we attempted to improve the students' web-based problem solving ability by applying an information summarising instruction strategy. The students were trained to identify the key points of the problems to be solved, evaluate the relevance of the searched web sites to the problems, and extract content from the web sites for giving quality answers.

\section{Participants}

Sixty-seven fifth graders, with an average age of 11, participated in the experiment. The students were randomly assigned to an experimental group $(n=34)$ and a control group $(\mathrm{n}=33)$.

\section{Experimental procedure}

In this study a pre-test and a post-test were conducted before and after the learning activity, respectively, to evaluate the information searching ability and content summarising ability of the students. During the learning activity, the students in the experimental group received the information summarising instructions as well as the instructions about the use of search engines, while the students in the control groups received only the instructions and practice using search engines. The research structure of the study is shown in Figure 1.

\section{Treatments}

The experimental group conducted the information summarising instruction strategy to deliver explicit skills and concepts for analysing an article. The control group adopted the conventional instruction strategy, i.e. the students were required to read an article freely in a restricted time period and then the teacher started articulating the important concepts and ideas of the article. 


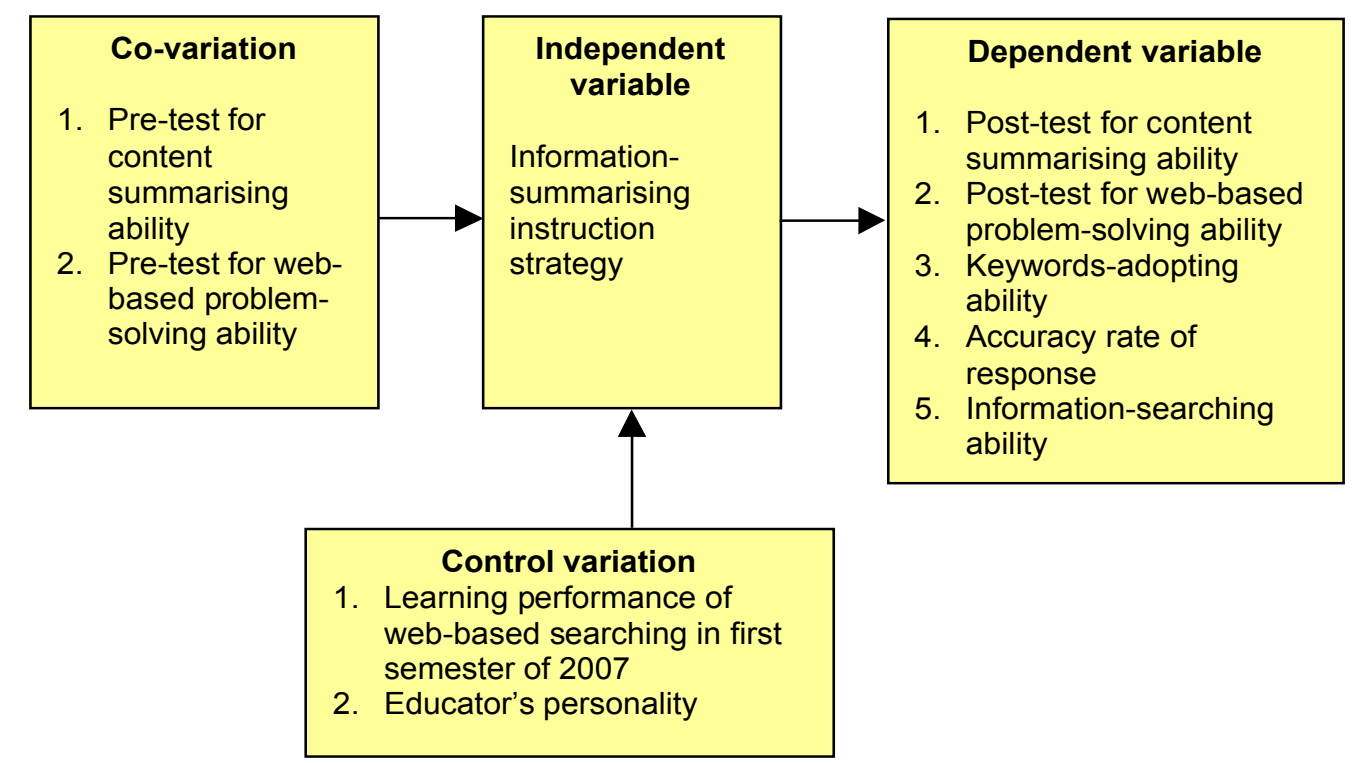

Figure 1: Research structure of the study

The process of the information summarising instruction strategy originated from the idea for summarising information proposed by Anderson and Hidi (1989), which consists of two stages, the information selection stage and the content reduction stage. The first denotes what content in an article should be kept or eliminated, while the second means that the low-level wording can be reduced and replaced with general ideas. In this study, the information summarising instruction strategy was conducted over a period of eight weeks with sixteen sessions to learn how to analyse three articles: "the largest lagoon in Taiwan", "the form of typhoon", and "the history of the aborigines in Taiwan," respectively. These particular articles were chosen by the students' senior elementary school teacher for their complex concepts, and more similar wordings, which need to be identified further. The three phases of information summarising strategy are described as follows:

\section{Interpretation and analysis}

This phase was conducted for two weeks using two sessions per week to guide learners to comprehend an article and identify the important concepts in each paragraph before summarising it. The article was related to a lagoon located in southern Taiwan. The teacher guided the students on how to look for and identify important ideas in the article with five "Wh-Questions" and one "H-Question" (Kintsch, 1990), as follows: (1) what is the topic of the article?; (2) who is the important figure in the article?; (3) why did those things occur in the article?; (4) where did the events occur?; (5) when did they occur?; and (6) how did they happen? In the first week, two forty-minute sessions were conducted for interpreting the article with the " $5 \mathrm{~W}+1 \mathrm{H}$ " approach. In the second week, two sessions were conducted for analysing the important concepts of each paragraph in the article.

\section{Selection and assessment}

This phase was managed for two weeks to show the learners how to determine and keep the important content of the article; that is, they need to judge what is irrelevant 
and get rid of it. This can also be done by using the five "Wh-Questions" and one "HQuestion."

\section{Induction and integration}

This phase was conducted for two weeks to teach the learners to find out any similar or repeated concepts, and to merge and reorganise them with their own ideas. The term "induction" means inducting complicated sentences with high-level concepts, while "integration" means that a learner can make sense of the article and integrate it with his/her own ideas into accurate and precise sentences.

Finally, the learners were asked to rehearse the three phases of information summarising skills by summarising two other articles in the last two weeks for review; one article was about aborigines in Taiwan, the other was about how typhoons were formed. In order to investigate how well students search and extract information about "nuclear power plants in Taiwan" on the web, a web information searching system, Meta-Analyzer developed by Hwang, Tsai, Tsai and Tseng (2008), was employed as a measuring tool for evaluating the selection of keywords, relevant websites, extracting and summarising information, as well as for measuring the web-based problem solving abilities of the students by recording the online problem solving behaviours of the students and providing several indicators to summarise those behaviors..

\section{Measuring tools}

In this study, two measurements are employed in the pre-test and the post-test; that is, the measurement of the students' content summarising efficacy and the measurement of their information searching ability. The former represents the summarising efficacy, while the latter represents the web-based problem solving ability of the students. These measurements are described in detail as follows.

\section{Measurement for content summarising efficacy}

The content summarising test originated from the study of Leslie and Caldwell (1995). Examples of summarising sentences were evaluated and decided on jointly by the teacher and students in the class, and were classified into three rating levels: 1, 2 and 3 representing "most important sentence", "important sentence" and "less important sentence", respectively. In addition to the rating scheme, this study adopted the formula of equation (1) for evaluating the students' content summarising efficacy. The formula is a modified version proposed by Head, Readence and Buss (1989) and adapted by Wei (2003). If most of the concepts of an article were presented with the least number of sentences, the learner would obtain a better score. That is, the higher the score the students get, the better efficacy they have (Head et al., 1989).

$$
\mathrm{SE}(\%)=\frac{\mathrm{ASE}}{\mathrm{ASA}}-\frac{\mathrm{AUSE}}{\mathrm{AUSA}}
$$

In this formula, the abbreviations of SE, ASE, AUSE, ASA, and AUSA denote "Summary Efficacy," "the Aggregate number of important SEntences," "the Aggregate number of Unimportant SEntences," "the Aggregate number of important Sentences in the Article," and "the Aggregate number of Unimportant Sentences in the Article," respectively. 
Measurement for information searching ability

The measurement for assessing students' information searching ability on the Internet originated from the study of Garner (1982). The formula for searching ability is shown as follows:

$$
\mathrm{SA}(\%)=\frac{\mathrm{AMC}}{\mathrm{ASW}} \times \frac{\mathrm{AMC}}{\mathrm{ACA}}
$$

In this formula, the abbreviations of SA, AMC, ASW, and ACA denote "Searching Ability", "the Aggregate number of Major Concepts in an article", "the Aggregate number of Summarised Words" and the "Aggregate number of Concepts in all the Answers", respectively.

\section{Learning environment for recording information searching behaviours}

In this study, a web information searching system, Meta-Analyzer, was implemented to assist educators in tracing and analysing the information searching behaviours of students (Hwang et al., 2008; Hwang \& Chen, 2010; Grimley \& Allan, 2010). For each learning activity, the system presents to the learners four questions prepared by the teachers. The first, second and third questions were structured in order to evaluate the information searching, extracting and summarising abilities of individual students, while the last one is an open ended question without any standard answer.

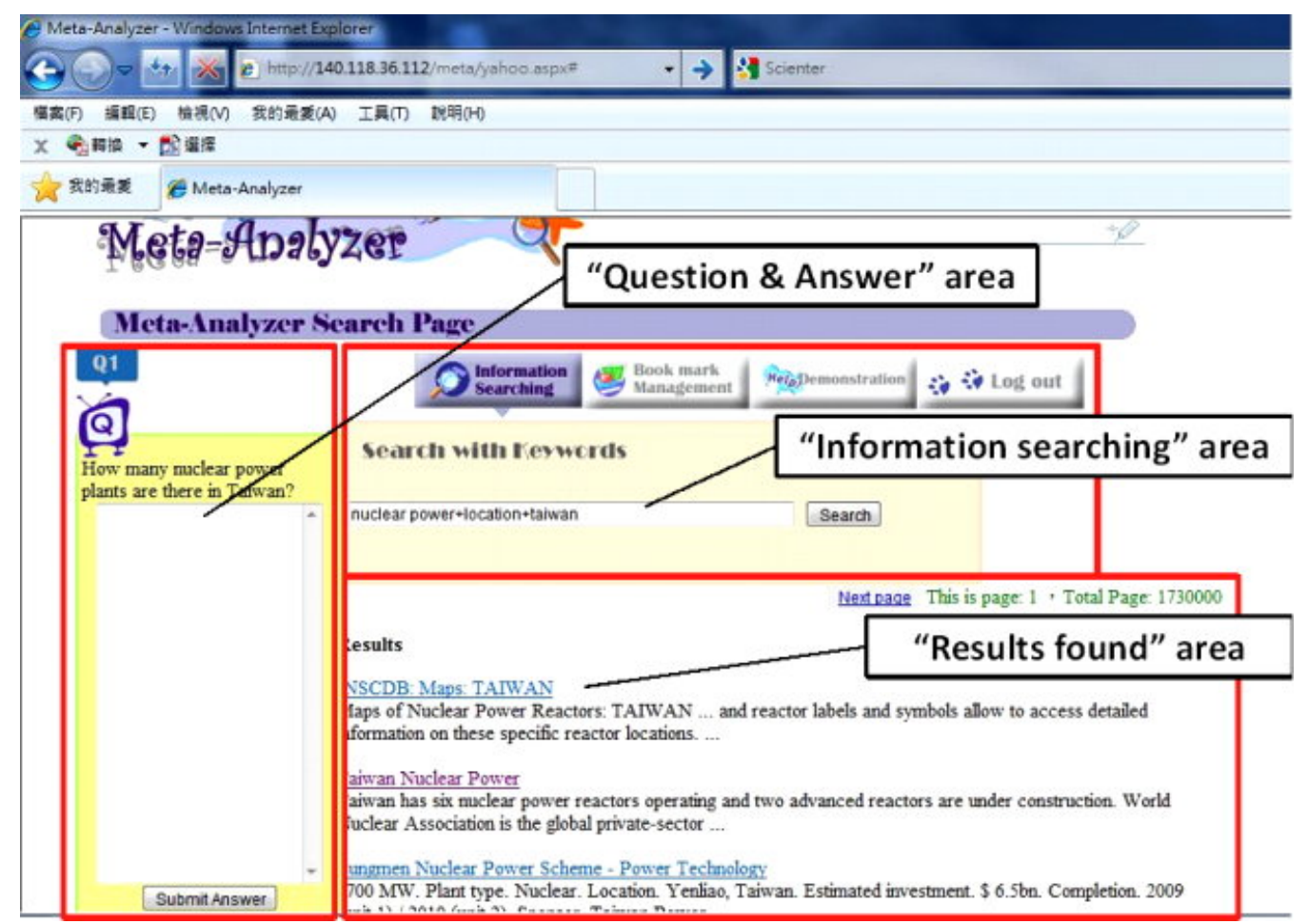

Figure 2: User interface of Meta-Analyzer 
Meta-Analyzer not only provides a problem solving environment, but also a search engine that enables students to search for appropriate data on the Internet. Moreover, all of the information searching behaviours of individual students are recorded. These records can be used by educators or researchers to reflect on their instruction strategies and materials, or to analyse the searching behaviours of the students.

Figure 2 shows the Meta-Analyzer interface for students, which consists of three areas: the "question and answer" area, the "information searching area" and the "search results" area, respectively. Learners, firstly, have to comprehend the question on the left of the screen. Based on the question, they have to adopt appropriate keywords to search for information; these keywords are shown in the top right of the screen. Then, the corresponding results will be returned by the search engine and shown in the bottom right of the screen.

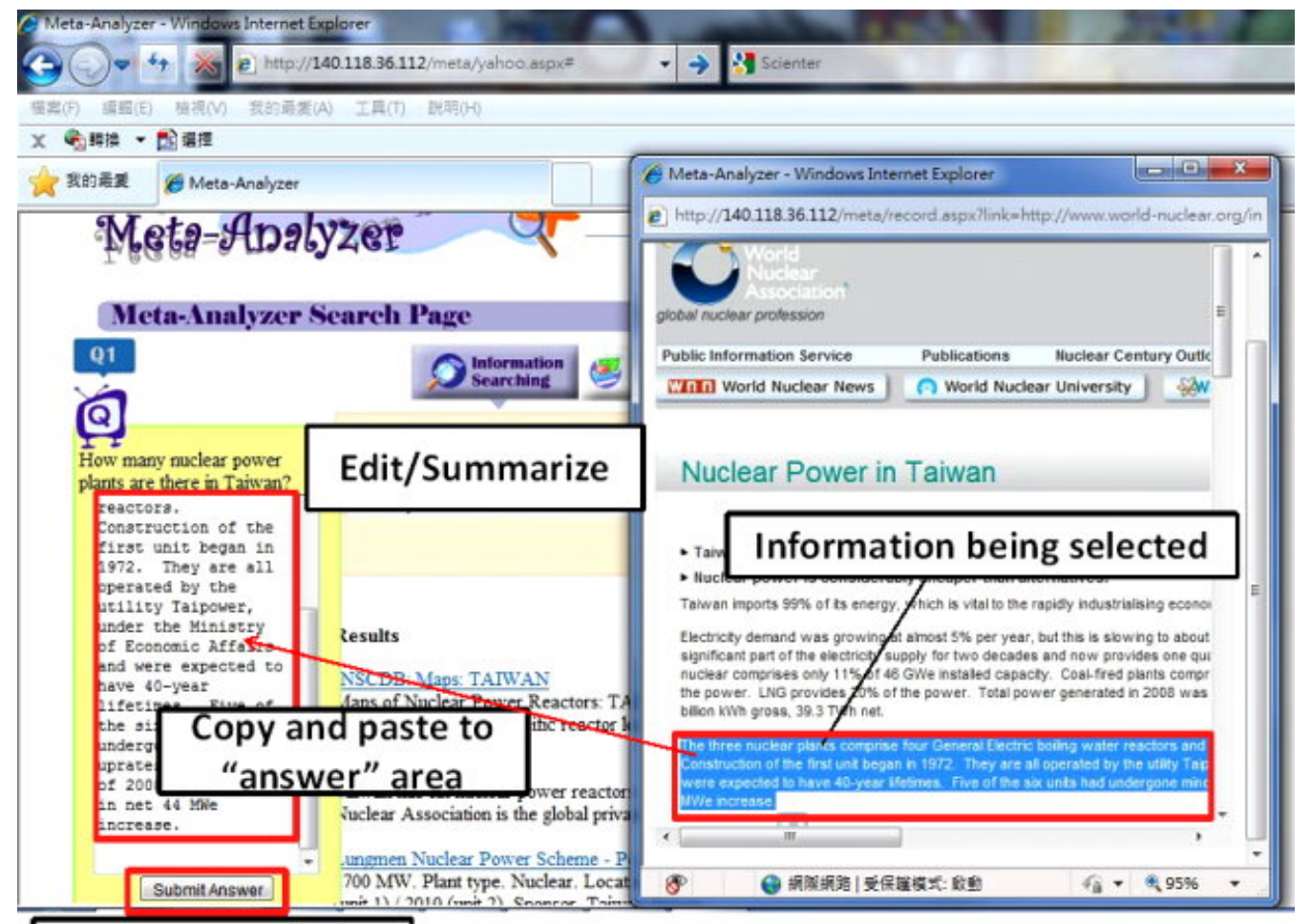

\section{Submit the answer}

Figure 3: Interface for searching for information and answering questions

While participating in the web-based problem solving activities, the students needed to analyse and make judgments of the questions raised by the teachers, and then determine the search strategy (i.e., the combinations of keywords) in order to find the needed information. Furthermore, the students needed to devise a strategy to efficiently find and extract the most relevant information from a number of web pages returned by the search engine. Therefore, the learning activities involve more than just searching for answers; instead, they are relevant to a series of problem solving steps, including understanding the questions, determining strategies for finding the needed 
information, selecting relevant web pages from the returned data, judging and extracting the needed information, reorganising the information extracted from different web pages, and stating their own opinions based on what they found on the web (Song, Grabowski, Koszalka \& Harkness, 2006). In essence, the activity designed with Meta-Analyzer is related to the aspect of problem solving (Jonassen, 2010).

An illustrative example of using Meta-Analyzer for searching for information and answering questions is given in Figure 3. Students can answer the questions by copying and pasting the selected information from the searched web pages to the answer area, modifying the collected information, and then submitting the answers.

Moreover, the educators are able to look into the information concerning the students' learning portfolio and searching behaviours from the system $\log$, such as the number of keywords used, the duration of browsing the adopted pages, as well as responses to the questions, to assess the students' learning efficacy. Figure 4 shows that educators can read the learning portfolios of individual students derived from the system log for further analysis and assessment.

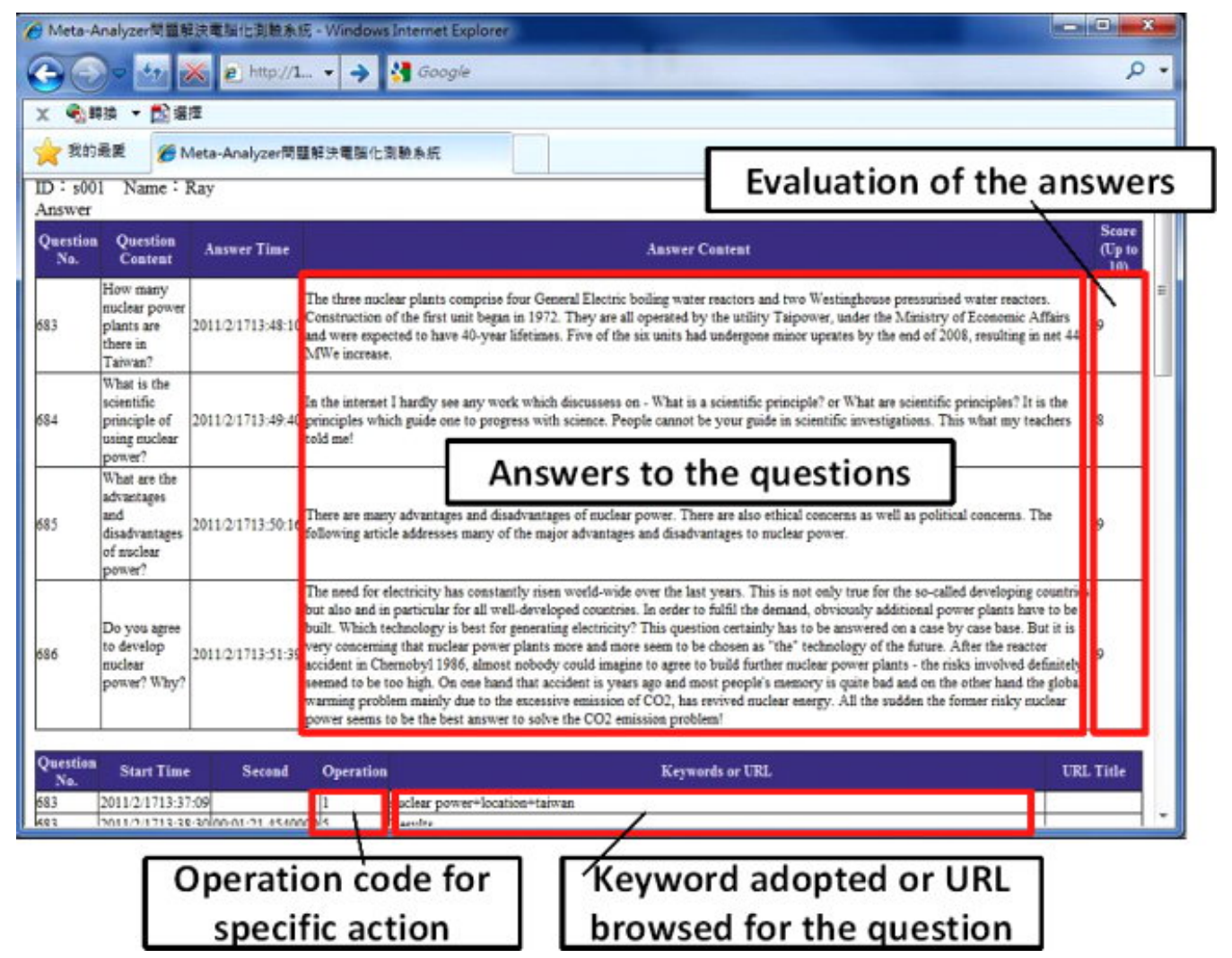

Figure 4: Student's searching portfolio recorded on Meta-Analyzer

As for the analysis function of Meta-Analyzer, a set of detailed quantitative indicators, called the "Web problem solving measure," is proposed based on the indicators suggested by Lin and Tsai (2005) and the user online behaviors attained from MetaAnalyzer, as shown in Figure 5. 


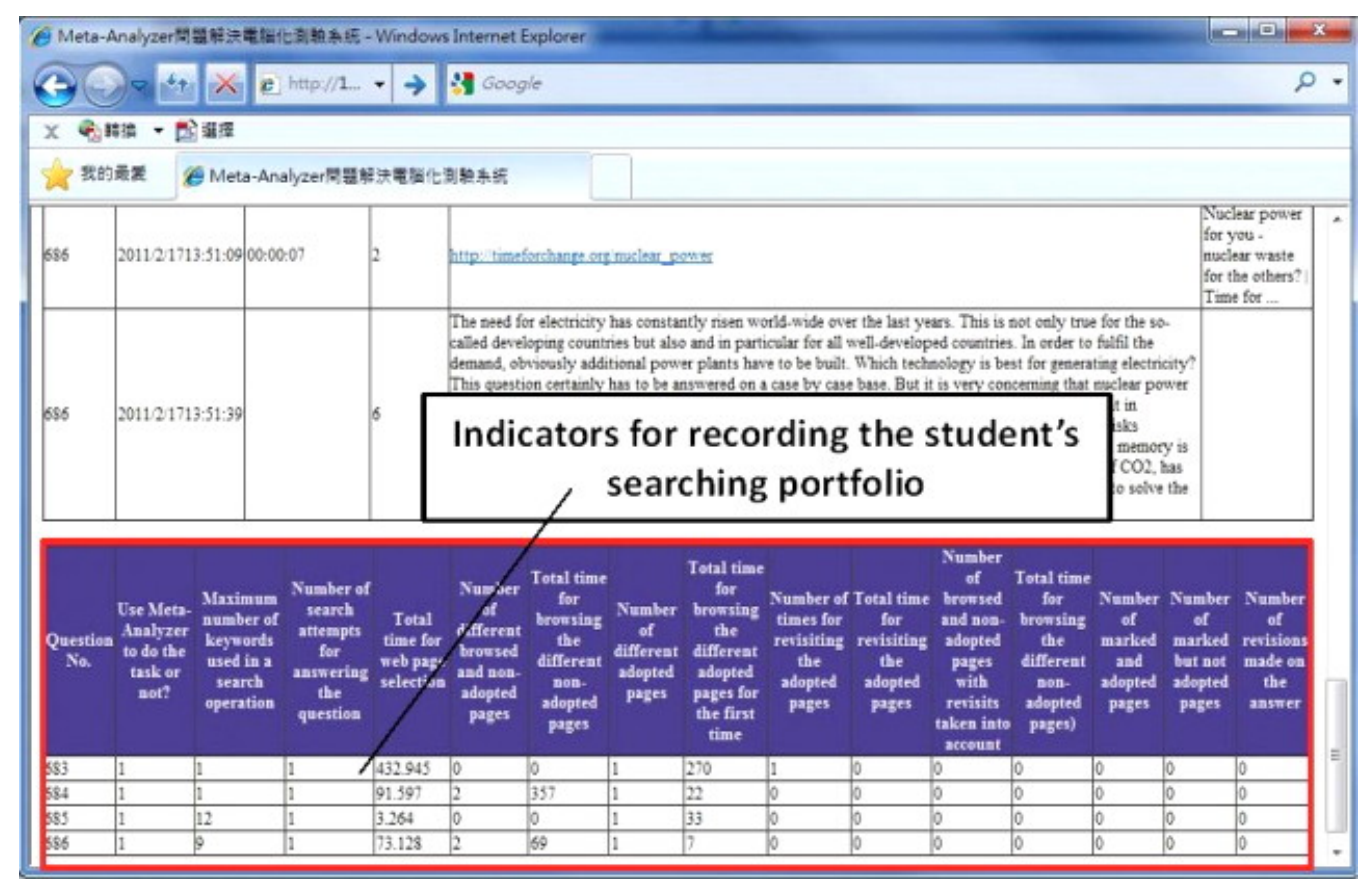

Figure 5: Indicators for student's searching portfolio

The new quantitative indicators are given as follows (Hwang et al., 2008):

- Number of keywords: shows the variations (number of different keywords used) for the learner to search for information to answer the question.

- Frequency of keywords: represents the frequency of the keywords used by the learner to search for information to answer the question.

- Time for web page selection: the time that the learner spends selecting a web page to browse the results returned by the search engine in order to answer the question.

- Time for surveying a selected page for the first time: hows the time the learner browses a selected page in order to answer the question. Note that it does not include the time taken to answer the question or to re-browse the same page.

- Number of pages: represents the number of different pages that are browsed by the user in order to answer the question.

- Number of adopted pages: represents the number of browsed pages that have been adopted by the learner in order to answer the question.

- Time for browsing the adopted pages: represents the time taken to browse the pages that have been adopted by the learner in order to answer the question.

- Number of revisited and adopted pages: represents the number of revisited pages that have been adopted by the learner to answer the question.

- Time for browsing the revisited and adopted pages: time taken to browse the revisited pages that have been adopted by the learner in order to answer the question.

- Number of revisited but not adopted pages: represents the number of revisited pages that have not been adopted by the learner to answer the question.

- Time for browsing the revisited but not adopted pages: represents the time taken to browse the revisited pages that have not been adopted by the learner to answer the question. 
- Number of marked and adopted pages: represents the number of web pages that have been marked and adopted by the learner to answer the question.

- Number of marked but not adopted pages: represents the number of web pages that have been marked but have not been adopted by the learner to answer the question.

- Number of revisions made to the answer: shows the number of revisions made by the learner to improve the quality of the answer to the question.

Thus, these statistical indicators are helpful to the instructors in understanding the web-searching behaviors and ability of the students (Tseng et al., 2009).

\section{Experimental results and discussion}

In this section, the experimental results are analysed based on three ability analyses, summarising ability, keyword adopting ability, and average number of keywords adopted. Moreover, the browsing efficacy, accuracy ratio of response, and web-based problem solving ability of the students are discussed as well. The descriptive statistical methods, one-way ANCOVA and Chi-square test, are employed to analyse the experimental outcomes of the study.

\section{Analysis of summarising ability}

Before conducting the information summarising instruction activity, two groups, one experimental and one control group, were given a pre-test, and required to do a posttest after the information summarising instruction session. Table 1 shows that the control group had no significant difference between the pre-test and post-test according to the statistical analysis of the paired samples t-test; however, the experimental group showed a significant difference comparing the pre-test with the post-test $(\mathrm{t}=-2.644, \mathrm{p}<.05)$, i.e., the experimental group had better performance in content summarising after the information summarising instruction.

Table 1: Paired samples t-test of the pre- and post-tests for the two groups

\begin{tabular}{|l|c|c|c|c|c|}
\hline \multicolumn{1}{|c|}{ Group } & $\mathrm{N}$ & Assessment & Mean & S.D. & $t$ \\
\hline \multirow{2}{*}{ Control group } & \multirow{2}{*}{33} & Pre-test & 0.465 & 0.290 & .785 \\
\cline { 3 - 5 } & & Post-test & 0.420 & 0.184 & \\
\hline Experimental group & \multirow{2}{*}{34} & Pre-test & 0.497 & 0.306 & \multirow{2}{*}{$-2.644^{*}$} \\
\cline { 3 - 5 } & & Post-test & 0.647 & 0.224 & \\
\hline
\end{tabular}

For further analysis, ANCOVA, was utilised to examine the difference in the content summarising ability between the control group and the experimental group. The pretest for summarising ability was used as the covariance, and the post-test was the dependent variable. Table 2 shows that the students in the experimental group had significantly better summarising ability than those in the control group $(\mathrm{F}=20.014$, $\mathrm{p}<.001)$. This result shows that the web-based problem solving activity is helpful to students in improving their summarising ability.

Table 2: ANCOVA of the summarising ability of the two groups

\begin{tabular}{|l|c|c|c|c|c|c|}
\hline \multicolumn{1}{|c|}{ Group } & $\mathrm{N}$ & Mean & S.D. & Adjusted mean & Std. error & Fvalue \\
\hline Control group & 33 & 0.42 & 0.183 & 0.422 & 0.35 & $20.014^{* * *}$ \\
\hline Experimental group & 34 & 0.647 & 0.224 & 0.645 & 0.35 & \\
\hline${ }^{* \star *} \mathrm{p}<.001$
\end{tabular}




\section{Keyword adopting ability}

Ratio of keyword adopting ability

The purpose of the test is mainly to examine students' keyword adopting ability in web searching after the information summarising instruction strategy. The pre-test of ratio of keyword adopting ability was used as the covariance, while the post-test was the dependent variable. Table 3 shows that the experimental group students had significantly better keyword adopting ability than those in the control group ( $\mathrm{F}=34.224$, $\mathrm{p}<.001)$. This result shows that the web-based problem solving activity is helpful to students in improving their keyword adopting ability.

Table 3: ANCOVA of the ratio of keyword adopted for the two groups

\begin{tabular}{|l|c|c|c|c|c|c|}
\hline \multicolumn{1}{|c|}{ Group } & $\mathrm{N}$ & Mean & S.D. & Adjusted mean & Std. error & F value \\
\hline Control group & 33 & 0.640 & 0.125 & 0.648 & 0.20 & \multirow{3}{*}{$34.224^{* * *}$} \\
\cline { 1 - 5 } Experimental group & 34 & 0.819 & 0.125 & 0.812 & 0.20 & \\
\hline$* * *$ p $<.001$
\end{tabular}

Average number of keywords adopted

The purpose of the test was to focus on the number of keywords adopted after the information summarising instruction. The pre-test of the number of keywords adopted is regarded as the covariance, while the post-test was the dependent variable. Table 4 shows that the experimental group students adopted a significantly lower average number of keywords than those in the control group $(\mathrm{F}=28.833, \mathrm{p}<.001)$. This result shows that the web-based problem solving activity is helpful to students in improving their ability to adopt keywords.

Table 4: ANCOVA of average number of keywords adopted by the two groups

\begin{tabular}{|l|c|c|c|c|c|c|}
\hline \multicolumn{1}{|c|}{ Group } & $\mathrm{N}$ & Mean & S.D. & Adjusted mean & Std. error & F value \\
\hline Control group & 33 & 10.351 & 1.783 & 10.204 & 0.242 & $28.833^{* * *}$ \\
\hline Experimental group & 34 & 8.218 & 1.324 & 8.362 & 0.238 & \\
\hline
\end{tabular}

\section{Information searching ability}

Information searching ability is measured by computing the accuracy ratio of the students' answers (Hwang et al., 2008). When the students searched for information from the Internet, they were required to retrieve information from the searched web pages with a limited number of words. Thus, the accuracy ratio of the words in the answers to the corresponding questions was calculated according to the word limit. The post-test of the accuracy ratio was used as the dependent variable, while the pretest was the covariant. Table 5 shows that the students in the experimental group had a significantly better accuracy ratio of students' answers than those in the control group $(\mathrm{F}=11.445, \mathrm{p}<.01)$. This result shows that the web-based problem solving activity is helpful to students in improving their accuracy ratio in responding to questions.

Table 5: ANCOVA of the accuracy ratio of responding to questions for the two groups

\begin{tabular}{|l|c|c|c|c|c|c|}
\hline \multicolumn{1}{|c|}{ Group } & $\mathrm{N}$ & Mean & S.D. & Adjusted mean & Std. error & F value \\
\hline Control group & 33 & 0.659 & 0.278 & 0.652 & 0.039 & \multirow{2}{*}{$11.445^{\star *}$} \\
\cline { 1 - 5 } Experimental group & 34 & 0.831 & 0.201 & 0.838 & 0.039 & \\
\hline${ }^{* *} \mathrm{p}<.01$
\end{tabular}




\section{Browsing efficacy}

Browsing efficacy is to measure one's efficiency while judging the first web site to browse after all of the searched pages displayed on the browser. This can be referred to understand a student's judgment in determining the first related web page. According to the descriptive statistics, Table 6 shows the mean scores for the experimental group and the control group in the pre- and post-tests, respectively. The post-test mean of the control group was higher than that of the pre-test, implying that the students did not gain better browsing efficacy after employing the traditional approach. On the other hand, the post-test mean of the experimental group was less than that of the pre-test, implying that the students improved their browsing efficacy after employing the information summarising instruction strategy. That is, the experimental group had better browsing efficacy skills after participating in the learning activity. In the process of selecting the web site to browse, the experimental group students were able to read the description of each candidate site shown on the "result found" area of MetaAnalyzer, and filter the irrelevant sites based on what they had learned in the "Interpretation and analysis" and "Selection and assessment" phases.

Table 6: Descriptive statistics of the browsing efficacy of the two groups

\begin{tabular}{|l|c|c|c|c|c|}
\hline \multirow{2}{*}{ Group } & \multirow{2}{*}{$\mathrm{N}$} & \multicolumn{2}{c|}{ Pre-test } & \multicolumn{2}{c|}{ Post-test } \\
\cline { 3 - 6 } & & Mean & S.D. & Mean & S.D. \\
\hline Control group & 33 & 469.48 & 180.4 & 533.80 & 331.86 \\
\hline Experimental group & 34 & 566.27 & 284.63 & 490.82 & 222.07 \\
\hline
\end{tabular}

\section{Web-based problem solving ability}

Web-based problem solving ability describes one's ability in retrieving critical information or concepts from the open resource to respond to questions. That is, students are likely to search for and retrieve information from the Internet with any number of words to solve the problems. Thus, the accuracy ratio of responding to questions was computed in accordance without a limited number of words, which is also regarded as "Web-based problem solving ability." Table 7 shows that the students in the experimental group had significantly better web-based problem solving ability than those in the control group $(\mathrm{F}=10.163, \mathrm{p}<.01)$. Thus, this result shows that the webbased problem solving activity is able to facilitate students in improving their webbased problem solving ability.

Table 7: ANCOVA of the web-based problem solving ability of the two groups

\begin{tabular}{|l|c|c|c|c|c|c|}
\hline \multicolumn{1}{|c|}{ Group } & $\mathrm{N}$ & Mean & S.D. & Adjusted mean & Std. error & F value \\
\hline Control group & 33 & 2.836 & 1.004 & 2.847 & 0.216 & $10.163^{* *}$ \\
\hline Experimental group & 34 & 3.831 & 1.395 & 3.821 & 0.212 & \\
${ }^{* *} \mathrm{p}<.01$
\end{tabular}

\section{Attitudes toward the information summarising instruction strategy}

After conducting eight weeks of sixteen sessions on the information summarising instruction strategy, participants were asked to fill out a questionnaire concerning their attitudes toward the instruction strategy. Table 8 shows the feedback from the students. Over $90 \%$ of the students agreed that the information summarising instruction strategy was helpful to them in adopting keywords; $82.3 \%$ indicated that they could find the websites they needed in a short time after the information 
summarising instruction. Moreover, it was helpful to $85.3 \%$ of them in extracting information from the web pages located by the search engine. To sum up, over $86 \%$ of the participants consented that the information summarising instruction strategy had improved their problem solving ability while searching for information on the Internet.

Table 8: Statistics of students' attitudes toward information summarising instruction strategy

\begin{tabular}{|l|c|c|c|c|c|c|}
\hline \multicolumn{2}{|c|}{ Rating level for helpfulness $(\mathrm{a})$} & 5 & 4 & 3 & 2 & 1 \\
\hline \multirow{2}{*}{ Keywords adopted } & $\mathrm{n}$ & 27 & 4 & 2 & 1 & 0 \\
\cline { 2 - 7 } & $\%$ & $79.4 \%$ & $11.8 \%$ & $5.9 \%$ & $2.9 \%$ & $0.0 \%$ \\
\hline \multirow{2}{*}{$\begin{array}{l}\text { Looking for important websites } \\
\text { in a short time }\end{array}$} & $\mathrm{n}$ & 18 & 10 & 3 & 3 & 0 \\
\hline & $\%$ & $52.9 \%$ & $29.4 \%$ & $8.8 \%$ & $8.8 \%$ & $0.0 \%$ \\
\hline \multirow{2}{*}{$\begin{array}{l}\text { Information extraction } \\
\text { Overall impression }\end{array}$} & $\mathrm{n}$ & 21 & 8 & 3 & 1 & 1 \\
\hline & $\mathrm{n}$ & $61.8 \%$ & $23.5 \%$ & $8.8 \%$ & $2.9 \%$ & $2.9 \%$ \\
\cline { 2 - 8 } & $\%$ & $64.7 \%$ & $21.6 \%$ & $7.8 \%$ & $4.9 \%$ & $1.0 \%$ \\
\hline
\end{tabular}

a. Rating level: 5=very helpful, $4=$ helpful, $3=$ more or less helpful, $2=$ less helpful, $1=$ not helpful

To sum up, the research findings show that the experimental group students had better web-based problem solving performance than the control group students in summarising ability, the adoption of keywords, accuracy ratio of response, and browsing efficacy after the intervention. These abilities mentioned above are all related to web-based problem solving ability. Thus, it can be concluded that the experimental group students are able to promote their web-based problem solving ability due to the assistance of the information summarising instruction strategy. Moreover, over $80 \%$ of the participants agreed that the information summarising instruction strategy had improved their problem solving ability while searching for information on the Internet.

\section{Conclusions}

This study aimed to improve the usage of keywords and information summarising abilities on the Internet for higher-grade elementary school students based on the information summarising instruction strategy. A quasi experiment with equivalent group pre- and post-test design was implemented, and 67 students were randomly divided into two groups, one experimental and one control group. The study attempted to investigate the difference between the two groups in terms of the keywords they adopted before and after the experiment. The statistical analysis method, one-way ANCOVA, was employed to examine the empirical findings, which are summarised as follows.

\section{Information summarising instruction improves students' summarising ability}

The research findings indicate that the experimental group has better scores for summary efficacy than the control group, with the average score improving markedly from 0.49 to 0.65 . With pencil and paper tests, low achievement students usually provide shorter answers when responding to questions than high achievement students; some of them even return blank sheets. However, the low achievement students in our study could use a few keywords in the information searching process after taking part in the information summarising instruction strategy. For instance, they already understood that the first sentence of every paragraph of an article is very 
important. Hence, their post-test score for summarising ability was better than their pre-test score for that particular aspect.

\section{Information summarising instruction improves students' keyword adopting ability}

The research findings show that the experimental group had better scores for keyword adoption than the control group. That is, the experimental group had better post-test scores with respect to the number of keywords adopted than in the pre-test after the information summarising instruction strategy. Moreover, the empirical results also showed that there exists a significant difference between the control group and the experimental group.

\section{Information summarising instruction improves students' accuracy ratio of response}

As for the students' accuracy ratio of response to an article with a limited number of words, the two groups showed a significant difference in the post-test. For the students in the experimental group, their usage of keywords and accuracy ratio of response had both made obvious improvements. They could also quickly find accurate answers from just a few web pages using important keywords.

\section{Information summarising instruction improves students' web-based problem solving ability}

In terms of the students' web-based problem solving ability from web pages with an unlimited number of words, the experimental group had better performance in the post-test scores than the control group. In other words, the information summarising instruction strategy resulted in a significant statistical difference between the control group and the experimental group, and improved their web-based problem solving abilities.

To sum up, the results of this study show that the learning performance of the experimental group students revealed better learning efficacy in keyword adoption, information searching, selecting and extracting, as well as problem solving abilities than those of the control group after participating in the web-based problem solving activity. Such a finding indicates that the intervention of the applied learning strategy had positive effects on the students in terms of identifying key concepts and ideas embedded in the content, comprehending learning materials, searching for relevant information for solving problems, judging and selecting valuable information from a large amount of data, and summarising the information based on the problem to be coped with. Consequently, it is worth trying to apply this approach to other science and social science courses in the future; in particular, the courses that aim to foster the students' abilities in solving practical problems.

\section{Acknowledgments}

The authors would like to thank Mr Meng-Chang Hsien, an elementary school teacher, for his assistance in conducting the instruction activity. This study is supported in part by the National Science Council of the Republic of China under contract number NSC 98-2511-S-011-008-MY3 and NSC97-2511-S-009-001-MY3. 


\section{References}

Anderson, V. \& Hidi, S. (1989). Teaching students to summarize. Educational Leadership, 46(4), 2628.

Ackerman, E. \& Karen H. (2005). Searching and researching on the Internet and the world wide web (4rd ed.). Wilsonville, OR: Franklin Beedle \& Associates.

Amadieu, F., Tricot, A. \& Mariné, C. (2009). Prior knowledge in learning from a non-linear electronic document: Disorientation and coherence of the reading sequences. Computers in Human Behavior, 25(2), 381-388.

Antiqueira, L., Oliveira Jr., O. N., Costa, L. F. \& Nunes, M. G. V. (2009). A complex network approach to text summarization. Information Sciences, 179(5), 584-599.

Bilal, D. (2000). Children's use of the yahooligans! Web search engine: 1. Cognitive, physical, and affective behaviors on fact-based search tasks. Journal of the American Society for Information Science, 51(7), 646-665.

Brickell, G. \& Herrington, J. (2006). Scaffolding learners in authentic, problem based e-learning environments: The Geography Challenge. Australasian Journal of Educational Technology, 22(4), 531-547. http: / / www.ascilite.org.au/ajet/ajet22/brickell.html

Cheng, G. (2009). Using game making pedagogy to facilitate student learning of interactive multimedia. Australasian Journal of Educational Technology, 25(2), 204-220. http: / / www.ascilite.org.au/ajet/ajet25/cheng.html

Chiou, C. K., Hwang, G. J. \& Tseng, J. C. R (2009). An auto-scoring mechanism for evaluating problem-solving ability in a web-based learning environment. Computers $\mathcal{E}$ Education, 53(2), 261-272.

Garner, R. (1982). Efficient text summarization: Costs and benefits. Journal of Educational Research, 75(5), 275-279.

Grimley, M. \& Allan, M. (2010). Towards a pre-teen typology of digital media. Australasian Journal of Educational Technology, 26(5), 571-584. http:/ / www.ascilite.org.au/ajet/ajet26/grimley.html

Hare, V. C., Rabinowitz, M. \& Schieble, K. M. (1989). Text effects on main idea comprehension. Reading Research Quarterly, 24, 72-88.

Head, M. H., Readence, J. E. \& Buss, R. R.(1989). An examination of summary writing as a measure of reading comprehension. Literacy Research and Instruction, 28(4), 1-11. http: / / pdfserve.informaworld.com/458384_918938007.pdf

Hwang, G. J. \& Chang, H. F. (2011). A formative assessment-based mobile learning approach to improving the learning attitudes and achievements of students. Computers $\mathcal{E}$ Education, 56(1), 1023-1031.

Hwang, G. J. \& Chen, J. (2010). A learning portfolio management system for analyzing student web-based problem-solving behaviors. In J. Liebowitz \& M. S. Frank (Eds), Knowledge management and e-learning. (pp. 81-92). Auerbach Publications. http: / / www.crcnetbase.com/doi/abs/10.1201/b10347-9

Hwang, G. J., Tsai, P.S., Tsai, C. C. \& Tseng, J. C.R. (2008). A novel approach for assisting teachers in analyzing student information searching behaviors. Computers $\mathcal{E}$ Education, 51, 926-938.

Jonassen, D. H. (2010). Learning to solve problems: A handbook. New York: Routledge. 
Kintsch, E. (1990). Macroprocess and microprocess in the development of summarization skill. Cognition and Instruction, 7(3), 161-195.

Ladbrook, J. \& Probert, E. (2011). Information skills and critical literacy: Where are our digikids at with online searching and are their teachers helping? Australasian Journal of Educational Technology, 27(1), 105-121. http:/ / www.ascilite.org.au/ ajet/ ajet27/ladbrook.html

Lorenzen, M. (2002). The land of confusion? High school students and their use of the World Wide Web for research. Research Strategies, 18(2), 151-163.

Leslie, J. L. \& Caldwell, J. (1995). Qualitative reading inventory-II (pp. 293-319). NY: Harper Collins College Publishers.

Lin, C. C. \& Tsai, C. C. (2005). Navigation flow map method of representing students' searching strategies on the Web. Paper presented at 2005 World Conference on Educational Multimedia, Hypermedia \& Telecommunications, Montreal, Canada.

Liu, G. Z., Liu, Z. H. \& Hwang, G. J. (2011). Developing multi-dimensional evaluation criteria for English learning websites with university students and professors. Computers $\mathcal{E}$ Education, 56(1), 65-79.

MaKinster, J. G., Beghetto, R. A. \& Plucker, J. A. (2002). Why can't I find Newton's third law? Case studies of students' use of the Web as a science resource. Journal of Science Education and Technology, 11(2), 155-172.

Madrid, R. I., Oostendorp, H. V. \& Melguizo, M. C. P. (2008). The effects of the number of links and navigation support on cognitive load and learning with hypertext: The mediating role of reading order. Computers in Human Behavior, 25(1), 66-75.

Pharo, N. \& Järvelin, K. (2004). The SST method: A tool for analysing Web information search processes. Information Processing \& Management, 40(4), 633-654.

Susar, F. \& Akkaya N. (2009). University students for using the summarizing strategies. Procedia - Social and Behavioral Sciences, 1(1), 2496-2499. [verified 3 Apr 2011] http: / / dx.doi.org/10.1016/j.sbspro.2009.01.440

Spink, A. \& Xu, J. L. (2000). Selected results from a large study of Web searching: The Excite study. Information Research: An International Electronic Journal, 6(1), 90. http: / / informationr.net/ir/6-1/ paper90.html

So, H. J. \& Kim, B. (2009). Learning about problem based learning: Student teachers integrating technology, pedagogy and content knowledge. Australasian Journal of Educational Technology, 25(1), 101-116. http: / / www.ascilite.org.au/ajet/ajet25/ so.html

Song, H., Grabowski, B., Koszalka, T. \& Harkness, W. (2006). Patterns of instructional design factors prompting reflective thinking in middle school and college level problem-based learning environments. Instructional Science, 34(1), 63-87.

Tu Y. W., Shih, M. \& Tsai C. C. (2008). Eighth graders' web searching strategies and outcomes: The role of task types, web experiences and epistemological beliefs. Computers $\mathcal{E}$ Education, 51(3), 1142-1153.

Tseng, J. C.R., Hwang, G. J., Tsai, P. S. \& Tsai, C. C. (2009). Meta-analyzer: A web-based learning environment for analyzing student information searching behaviors. International Journal of Innovative Computing, Information and Control, 5(3), 567-579.

Tsai, M. J. \& Tsai, C. C. (2003). Information searching strategies in web-based science learning: The role of Internet self-efficacy. Innovations in Education and Teaching International, 40(1), 4350. 
Tsai, P. S., Tsai, C. C. \& Hwang, G. J. (2011). The correlates of Taiwan teachers' epistemological beliefs concerning Internet environments, online search strategies, and search outcomes. The Internet and Higher Education, 14, 54-63.

Veletsianos, G. \& Doering, A. (2010). Long-term student experiences in a hybrid, open-ended and problem based Adventure Learning program. Australasian Journal of Educational Technology, 26(2), 280-296. http:/ / www.ascilite.org.au/ajet/ajet26/veletsianos.html

Wallace, R. M., Kupperman, J., Krajcik, J. \& Soloway, E. (2000). Science on the Web: Students online in a sixth-grade classroom. The Journal of the Learning Sciences, 9(1), 75-104.

Washington, E. (1977). Wh-Questions in teaching composition: Staffroom interchange. College Composition and Communication, 28(1), 54-56.

Williams, J. P., Taylor, M. B. \& DeCani, J. S. (1984). Constructing macro structure for expository text. Journal of Educational Psychology, 76, 1065-1075.

Wormeli, R. (2005). Summarization in any subject: 50 techniques to improve student learning. Alexandria, VA: Association for Supervision and Curriculum Development (ASCD).

Wu, Y. T. \& Tsai, C. C. (2007). Developing an Information Commitment Survey for assessing students' web information searching strategies and evaluative standards for web materials. Educational Technology \& Society, 10(2), 120-132. http:/ / www.ifets.info/journals/10_2/11.pdf

Wei, C. W. (2003). The effects of mind mapping and summary instruction on reading comprehension and summarizing ability of fifth graders in elementary school (unpublished dissertation). National Taiwan Normal University, Taiwan.

Authors: Gwo-Jen Hwang, Chair Professor

Graduate Institute of Digital Learning and Education

National Taiwan University of Science and Technology

43, Sec.4, Keelung Rd, Taipei, 106, Taiwan

Email: gjhwang.academic@gmail.com

Fan-Ray Kuo, PhD student

Department of Information and Learning Technology

National University of Tainan

33, Sec. 2, Shulin St, Tainan city 70005, Taiwan

Email: revonkuo@gmail.com

Please cite as: Hwang, G.-J. \& Kuo, F.-R. (2011). An information-summarising instruction strategy for improving the web-based problem-solving abilities of students. Australasian Journal of Educational Technology, 27(2), 290-306.

http:/ / www.ascilite.org.au/ajet/ajet27/hwang.html 